\title{
Winter warming in West Antarctica caused by central tropical Pacific warming
}

\author{
Qinghua Ding ${ }^{1}$, Eric J. Steig ${ }^{1 \star}$, David S. Battisti² and Marcel Küttel ${ }^{1}$
}

\begin{abstract}
The Pacific sector of Antarctica, including both the Antarctic Peninsula and continental West Antarctica, has experienced substantial warming in the past 30 years. An increase in the circumpolar westerlies, owing in part to the decline in stratospheric ozone concentrations since the late 1970s, may account for warming trends in the peninsula region in austral summer and autumn. The more widespread warming in continental West Antarctica (Ellsworth Land and Marie Byrd Land) occurs primarily in austral winter and spring, and remains unexplained. Here we use observations of Antarctic surface temperature and global sea surface temperature, and atmospheric circulation data to show that recent warming in continental West Antarctica is linked to sea surface temperature changes in the tropical Pacific. Over the past $\mathbf{3 0}$ years, anomalous sea surface temperatures in the central tropical Pacific have generated an atmospheric Rossby wave response that influences atmospheric circulation over the Amundsen Sea, causing increased advection of warm air to the Antarctic continent. General circulation model experiments show that the central tropical Pacific is a critical region for producing the observed high latitude response. We conclude that, by affecting the atmospheric circulation at high southern latitudes, increasing tropical sea surface temperatures may account for West Antarctic warming through most of the twentieth century.
\end{abstract}

t has long been known that parts of the Antarctic Peninsula are warming rapidly ${ }^{1}$. Recently, it has been recognized that significant warming trends extend considerably south of the Peninsula to include much of continental West Antarctica ${ }^{2,3}$, comprised of Ellsworth Land $\left(\sim 79^{\circ} \mathrm{W}\right.$ to $\left.103^{\circ} \mathrm{W}\right)$ and Marie Byrd Land $\left(\sim 103^{\circ} \mathrm{W}\right.$ to $\left.158^{\circ} \mathrm{W}\right)$. West Antarctica is the key region for heat and moisture transport into Antarctica ${ }^{4}$, and the West Antarctic ice sheet has been losing mass in recent decades, primarily because of increased ice discharge through outlet glaciers that drain into the Amundsen Sea ${ }^{5}$. A change of regional climate over this region could have a substantial impact on the dynamics and mass balance of the Antarctic ice sheet, and consequently on global sea level.

Recent warming over the Antarctic Peninsula has been explained in part by a positive trend in the Southern Annular Mode (SAM), manifested as a strengthening of the circumpolar westerlies, and attributed to stratospheric ozone depletion and increasing greenhouse gases ${ }^{6,7}$. The SAM does not readily account for warming in continental West Antarctica, however, because increased westerlies tend to cool, rather than warm, the Antarctic interior ${ }^{8,9}$. Furthermore, the positive trend in the SAM is restricted to summer and autumn ${ }^{7}$, whereas West Antarctic warming has occurred predominantly in winter and spring ${ }^{2,10}$.

Attention has also been given to the role of the El NiñoSouthern Oscillation (ENSO) in influencing Antarctic climate ${ }^{11-14}$. There is no significant trend in the Southern Oscillation Index or other indices of the main ENSO region (that is, the eastern tropical Pacific), suggesting at most a weak contribution to the recent warming trend in West Antarctica. However, changes in the tropical Pacific that are not directly related to ENSO also influence the high latitude circulation ${ }^{15-18}$. In particular, sea surface temperature (SST) anomalies under areas of strong tropical convection have a significant influence on atmospheric circulation in the Amundsen Sea region, through the generation of a large scale atmospheric wave $\operatorname{train}^{18}$. In this paper, we use both observations and modelling to show that SST trends in the central tropical Pacific account for warming trends in continental West Antarctica through this mechanism.

We rely primarily on post-1979 observations (see Methods), because climate-field data for the Southern Hemisphere $(\mathrm{SH})$ polar region exhibit large uncertainty and bias before the modern satellite era ${ }^{19}$. Both ECMWF (ref. 20) and NCEP2 (ref. 21) reanalysis data are consistent with satellite infrared data $^{2,22}$ and raw weather station data in showing that the greatest warming in Antarctica since 1979 has occurred in austral winter (JJA; Fig. 1) and spring (SON) (Supplementary Fig. S1). Although the magnitude of warming varies among data sets, with NCEP2 being the outlier (see Methods), all data sets show that winter and spring warming is concentrated in the Marie Byrd Land sector of West Antarctica. Although there is also winter and spring warming on the western Antarctic Peninsula, the widespread warming there occurs in autumn (MAM; Supplementary Fig. S1). Thus, the continental West Antarctic warming is distinct in seasonal character from the Antarctic Peninsula warming.

Warming in West Antarctica is observed both at the surface ${ }^{2,3}$ and throughout the troposphere ${ }^{10}$. Wintertime geopotential heights in the upper troposphere (Z200) have increased almost everywhere in the SH since 1979, with the greatest increases occurring over West Antarctica (Fig. 1). A similar change is observed in the middle troposphere and at the surface in winter (Fig. 1), as well as in spring (Supplementary Fig. S2).

\section{Covariance of SH circulation and tropical SST}

The observed increase in geopotential heights over West Antarctica is associated with changes in SST and related deep convection over parts of the tropical Pacific. To show this, we employ maximum covariance analysis (MCA; refs 23,24) of seasonal means of tropical SST and SH Z200 for the 31-year period, 1979-2009. Results obtained from MCA consist of pairs of spatial modes and corresponding time series, representing co-varying tropical SST and

${ }^{1}$ Quaternary Research Center and Department of Earth and Space Sciences, University of Washington, Seattle, Washington 98195, USA, ${ }^{2}$ Department of Atmospheric Sciences, University of Washington, Seattle, Washington 98195, USA. *e-mail: steig@uw.edu. 
a

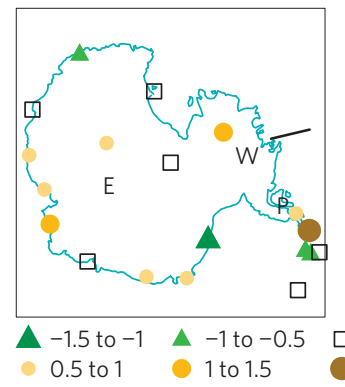

b

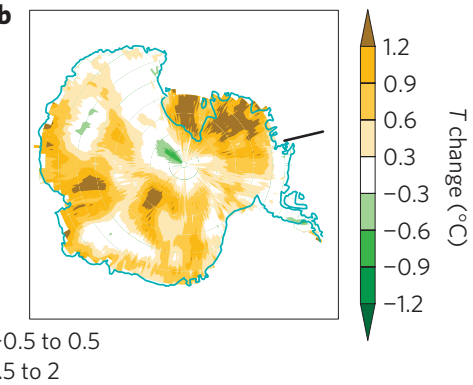

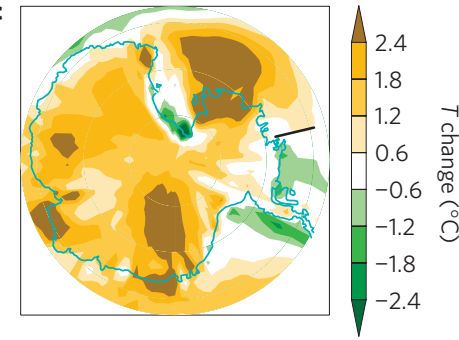

d
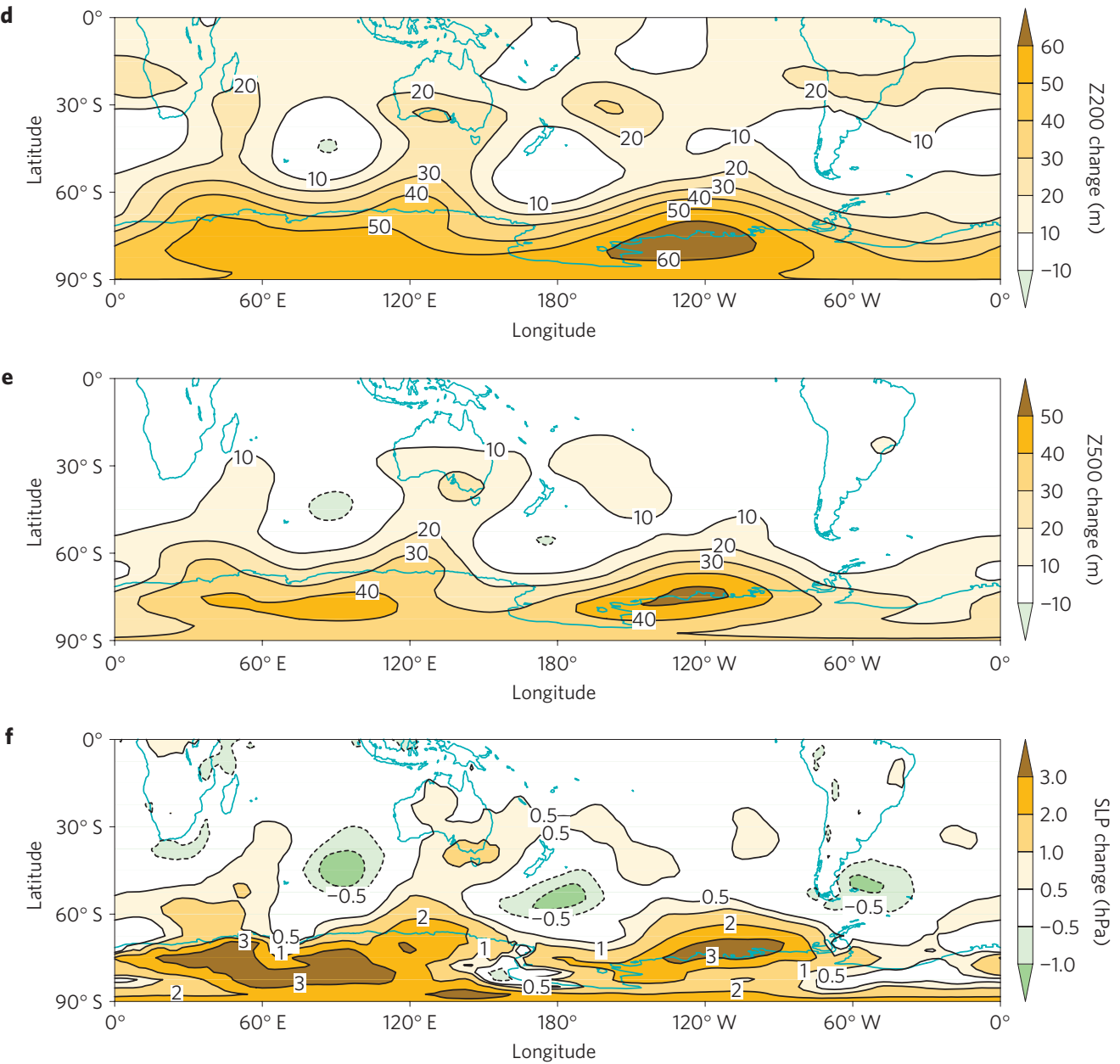

Figure 1 | Antarctic temperature and Southern Hemisphere circulation changes in austral winter. Top three panels show the epochal differences (late period minus early period) of winter (JJA) mean (a) near-surface temperature from weather stations, (b) surface temperature from AVHRR satellite data and (c) near-surface temperature from ECMWF reanalysis. ' $E$ ' and ' $W$ ', and ' $P$ ' denote the locations of East Antarctica, continental West Antarctica and the Antarctic Peninsula. The line shows the $\sim 103^{\circ} \mathrm{W}$ longitude separating Ellsworth Land to the east from Marie Byrd Land to the west. Note the different colour scales used for each temperature data set. Lower three panels show (d) $200 \mathrm{hPa}$ geopotential height, (e) $500 \mathrm{hPa}$ geopotential height and (f) sea level pressure. Epochs are 1994-2009 and 1979-1993 (1994-2006 and 1982-1993 for AVHRR).

SH Z200 structures. For the two fields analysed here, the tropical SST mode can be physically interpreted as the forcing, and the Z200 mode as the response ${ }^{25}$. Leading pairs of MCA patterns thus indicate those patterns of tropical SST anomalies that most strongly influence the $\mathrm{SH}$ extratropical circulation.

In winter, the first MCA mode (JJA mode 1) explains about $41 \%$ of the total covariance (Fig. 2). The SST pattern resembles the characteristic ENSO signature with positive SST anomalies centred over the eastern equatorial Pacific and negative SST anomalies over most of the remainder of the tropics. The corresponding Z200 pattern is dominated by a wave structure in the $\mathrm{SH}$ mid-latitudes and East Antarctica, with little change over West Antarctica.
The second wintertime MCA mode (JJA mode 2) explains 31\% of the covariance. In contrast with the first mode, the strongest signal in the SST pattern is a warming in the central tropical Pacific and the South Pacific convergence zone (SPCZ), with the corresponding Z200 pattern displaying a prominent poleward-arching wave train; as for mode 1 , the associated time series of these patterns are highly correlated $(r=0.82)$. The most southern cell of the wave train is an anomalous high over West Antarctica and the surrounding ocean. This wave train exhibits an approximately equivalent barotropic structure in the extratropics, and a phase reversal between upper troposphere and surface over the tropical central Pacific. This is indicative of a classic stationary Rossby wave response to tropical 


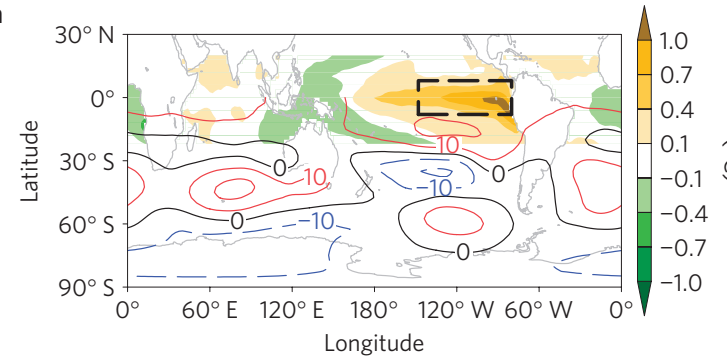

c
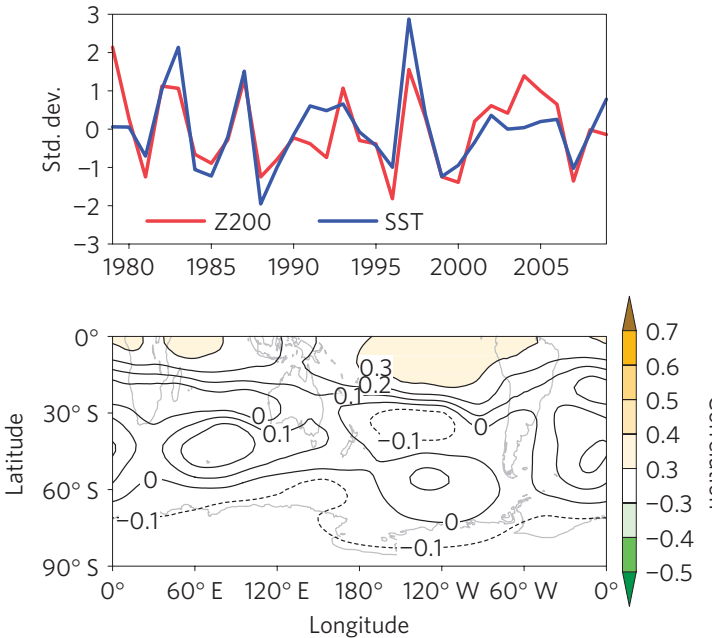

b

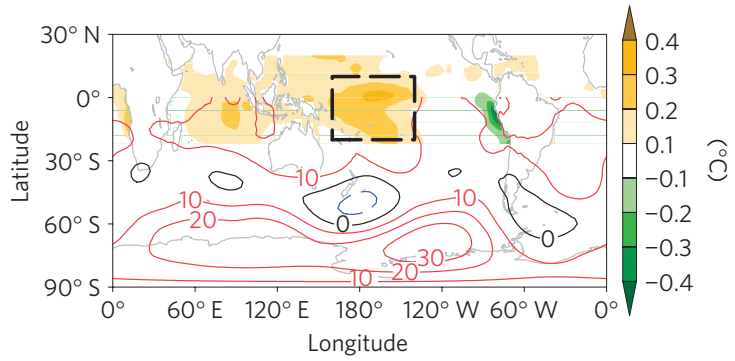

d

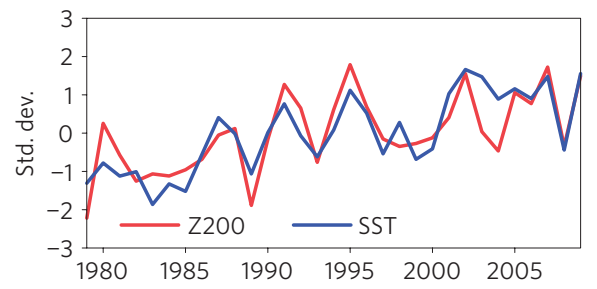

f

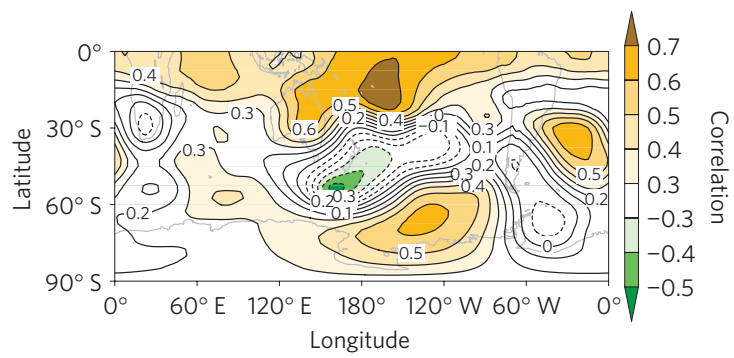

Figure 2 | Principal modes of covarying tropical sea surface temperature and Southern Hemisphere circulation in austral winter. Upper panels: spatial patterns of tropical SST (shading) and 200 hPa geopotential heights (Z200, contour interval 10 m) associated with (a) mode 1 and (b) mode 2. Middle panels: time series of SST and Z200 for (c) mode 1 and (d) mode 2. Lower panels: correlation between Z200 and SST averaged over (e) the eastern tropical Pacific (area outlined in $\mathbf{a}$ ), and (f) the central tropical Pacific (outlined in $\mathbf{b}$ ). Amplitudes in $\mathbf{a}$ and $\mathbf{b}$ are scaled by one standard deviation of the corresponding time series in $\mathbf{c}$ and $\mathbf{d}$.

SST forcing ${ }^{26,27}$. The large amplitude of circulation over West Antarctica agrees well with theoretical understanding of tropically forced stationary Rossby waves, namely, a poleward increase in the amplitude of geopotential height anomalies ${ }^{28}$. Also important, the JJA mode 2 wave train pattern closely resembles the pattern of the wintertime $\mathrm{Z} 200$ trend in the $\mathrm{SH}$ (spatial correlation = 0.7) and the trend in the time series of mode 2 indicates that this pattern captures the primary long-term change of SH Z200 over the past 30 years.

The JJA mode 2 time series are highly correlated with surface temperature changes in West Antarctica (Fig. 3), with the greatest covariance in the Marie Byrd Land sector, where the observed long-term temperature trends are also the greatest in all data sets (Supplementary Fig. S1). The mode 2 time series are also significantly correlated with sea ice anomalies adjacent to West Antarctica. (The dipole-like sea ice anomaly pattern is also captured as the first principal component of Antarctic winter sea ice variability, which accounts for $26 \%$ of the total variance; this pattern has previously been linked to tropical Pacific forcing ${ }^{29}$.) The dynamics responsible for this relationship are clear: strong anticyclonic circulation anomalies over West Antarctica are associated with anomalous onshore wind to the west and offshore wind to the east, providing favourable conditions for the movement of sea ice toward the Amundsen Sea coast (decreasing sea ice concentration) and offshore (increasing sea ice concentration) movement in the Bellingshausen Sea.

An important aspect of these results is that the SST forcing that seems to explain the circulation and temperature trends in continental West Antarctica is not directly related to changes in the eastern tropical Pacific ENSO region. Although the mode 2 wave train pattern is comparable to the Pacific South America pattern that has been identified as the primary $\mathrm{SH}$ teleconnection

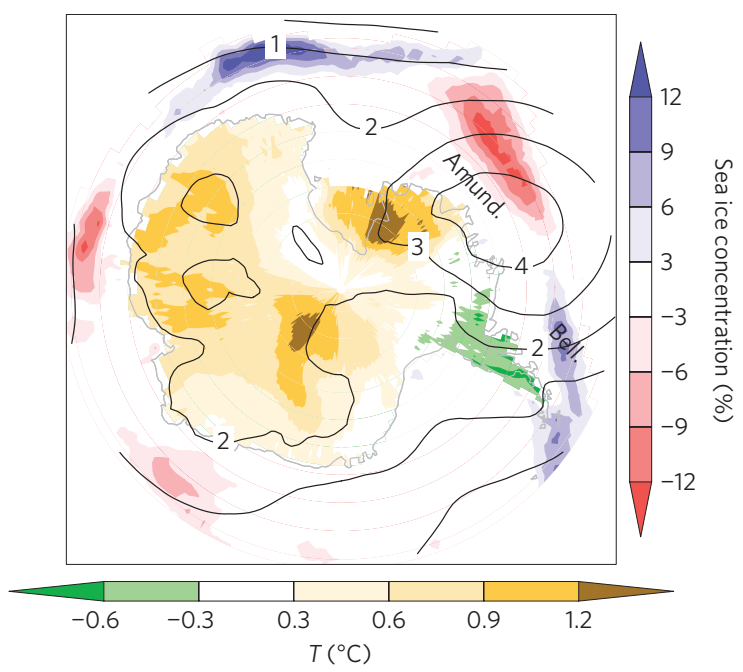

Figure 3 | Relationship between Southern Hemisphere circulation and West Antarctic climate in austral winter. Figure shows the regression of austral winter mode 2 Z200 time series from maximum covariance analysis against independent AVHRR surface temperature (brown and green shading), sea ice concentration (red and blue shading) and sea level pressure (contour interval $1 \mathrm{hPa}$ ). 'Amund.' = Amundsen Sea; 'Bell.' = Bellingshausen Sea.

associated with ENSO forcing ${ }^{11}$, it is not significantly correlated with ENSO indices. Similarly, the spatial patterns of correlations between tropical SSTs and SH Z200 demonstrate a much stronger teleconnection of the West Antarctic region with the tropical central 
a

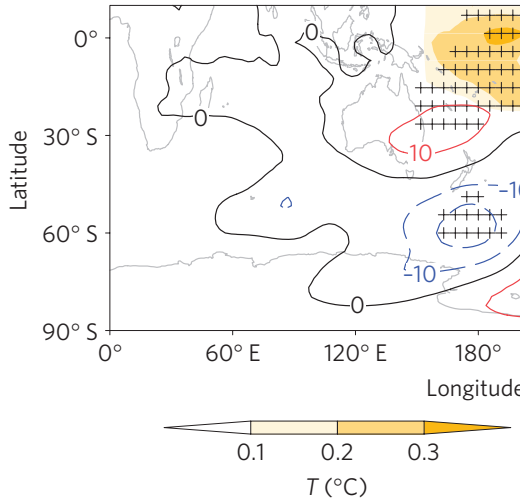

b

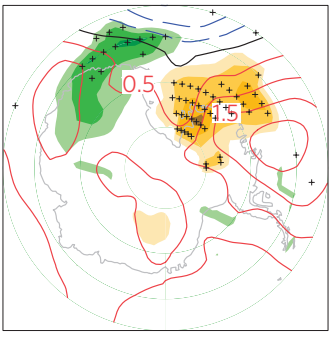

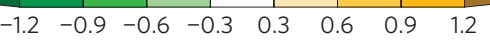

Figure 4 | Response of ECHAM4.6 atmospheric model to anomalous warm central Pacific sea surface temperature in austral winter. a, 200 hPa

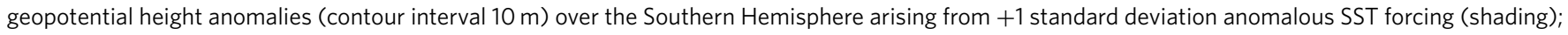
b, sea level pressure anomalies (contour interval $0.5 \mathrm{hPa}$ ) and surface temperature anomalies (shading) in the Antarctic region. Crosses denote regions of Z200 anomalies in $\mathbf{a}$ and surface temperature anomalies in $\mathbf{b}$, where the model response is above the $99 \%$ confidence level as assessed by a two-tailed Student's t-test.

Pacific than with the classic ENSO region (Fig. 2e,f). Thus, whereas SST variability in both the central and eastern tropical Pacific drive extratropical circulation anomalies, it is the central Pacific SST anomalies that have the greatest influence on continental West Antarctic climate.

\section{Model response to tropical SST forcing in austral winter}

The empirical results are a strong indication that the observed JJA warming over West Antarctica in the past 30 years is primarily owing to the high latitude atmospheric circulation response to SST changes in the central tropical Pacific. To test this inferred causal relationship, we use the ECHAM4.6 atmospheric general circulation model ${ }^{30}$ with specified SST anomalies as a boundary condition. We use the observed climatological seasonal SST cycle to obtain the model's mean climate, which constitutes our control run. We perform a second run by using the same climatological SSTs augmented by the SST pattern from JJA mode 2 in the central Pacific (that is, within the dashed box in Fig. 2b), with an amplitude of +1 standard deviation applied from June 1 to August 31. These experiments were integrated 50 times with different atmospheric initial conditions, forming 50 independent realizations of the atmospheric response. The ensemble mean is used to assess the robust response of ECHAM4.6 to the specified anomalous SST forcing.

The JJA seasonal mean difference of the upper level height, sea level pressure and surface temperature between the forced and control run are shown in Fig. 4. The model response depicts a prominent well-organized wave train pattern propagating from the tropical central Pacific to West Antarctica along a 'great circle' path. There is good agreement between this simulated wave train and its observed counterpart. Particularly noteworthy is the surface warming in Marie Byrd Land and the adjacent ocean caused by the anomalous anticyclonic cell over West Antarctica. This experiment provides support for our interpretation that the JJA SST forcing over the central tropical Pacific can explain the observed circulation and surface temperature response in West Antarctica. Additional model runs used to examine the $\mathrm{SH}$ circulation response to SST forcing over the Indian Ocean and ENSO forcing in the equatorial eastern Pacific similarly support our empirical results that circulation changes over continental West Antarctica are not strongly sensitive to SST anomalies in those regions (Supplementary Fig. S3).

The magnitude of the response to central Pacific SST forcing is in good agreement with the observed changes in both surface temperature and circulation over West Antarctica. Specifically, the magnitude of the SST anomalies used as forcing for the ECHAM4.6 atmospheric general circulation model is equivalent to 1 standard deviation of the JJA mode 2 SST time series (Fig. 2d). The epochal difference (1994-2009 - 1979-1993) of the same times series is $\sim 1.3$ standard deviations. The model response, scaled by a factor of 1.3 , is thus directly comparable to the observed epochal differences shown in Fig. 1. The scaled temperature response is $\sim 1.3^{\circ} \mathrm{C}$ averaged over all of continental West Antarctica, and the observed temperature change over the same domain is similar at $\sim 0.9^{\circ} \mathrm{C}$ for the AVHRR data and $\sim 1.5^{\circ} \mathrm{C}$ for ECMWF; only NCEP2 data show a substantially different magnitude of change $\left(\sim 3.7^{\circ} \mathrm{C}\right)$. At Byrd Station $\left(80^{\circ} \mathrm{S}, 120^{\circ} \mathrm{W}\right)$ the model response is $1.4^{\circ} \mathrm{C}$, versus $1.1^{\circ} \mathrm{C}$ in the observations. The sea level pressure response is $\sim 2 \mathrm{hPa}$, and the observed change is $\sim 1-3 \mathrm{hPa}$. Thus, the model both qualitatively and quantitatively reproduces the observed trends.

We also ran the ECHAM 4.6 model with a full 31 years (1979-2009) of observed SSTs changes in the central tropical Pacific (within box in Fig. 2b), rather than the idealized one-standard-deviation anomaly described above, as boundary conditions. Climatological SSTs are used outside the central tropical Pacific. This produces very similar results, but with a spatial pattern of temperature response in Antarctica that is qualitatively in better agreement with observations (Supplementary Fig. S4a), including more widespread winter warming eastward toward the Antarctic Peninsula, as well as on the Peninsula itself. The mean winter response for continental West Antarctica is $1.4^{\circ} \mathrm{C}$ (1994-20091979-1993). In contrast, running the model using climatological SSTs in the central tropical Pacific, and observed 31-years SSTs everywhere else, produces both circulation patterns and temperature patterns in West Antarctica (Supplementary Fig. S4b) that are strongly at odds with the observations. In particular, the mean response is much weaker $\left(0.3^{\circ} \mathrm{C}\right)$, cooling occurs in that area of West Antarctica where observed warming is strongest, and circulation anomalies are of opposite sign to those observed. These results further demonstrate the fundamental role played by tropical forcing in explaining recent West Antarctic temperature and circulation trends.

\section{Observations and simulations in austral spring}

Warming in West Antarctica in austral spring ( $\mathrm{SON}$ ) also seems to be linked with the central tropical Pacific, but with some important differences compared with winter. Analysis of Southern Hemisphere $200 \mathrm{hPa}$ heights and tropical SST in spring, again using maximum covariance analysis, yields a pair of mode 2 patterns (Supplementary Fig. S5) that feature strong trends in tropical SST and SH circulation closely associated with surface temperatures in 
West Antarctica and sea ice variability in the adjacent ocean. As in winter, the mode 2 pattern in spring is similar to the observed trend in circulation. Thus, the dominant patterns of joint tropical SST and high latitude circulation, identified empirically, account for the observed spring warming in West Antarctica in the independent surface temperature data. However, the SST anomalies for spring are centred in the SPCZ region, rather than along the equator.

Previous work has shown that SST anomalies in the SPCZ region do not tend to create Rossby wave trains ${ }^{13}$. We find that prescribing the SST pattern (SON mode 2) identified from maximum covariance analysis for spring under the ECHAM4.6 atmospheric model can reproduce the observed circulation patterns; a comparable result is obtained with a run using 31 years of observed SSTs. In both cases, however, the response is weaker than for winter, and is not statistically significant (Supplementary Fig. S6). Thus, although the spring warming trend in West Antarctica is clearly related to strong regional circulation anomalies that covary with tropical SSTs, these anomalies are not as definitively explained by tropical forcing in spring as they are in winter.

\section{Long-term trends}

Our analyses and modelling results show that recent West Antarctic warming trends in austral winter, and to a lesser extent in spring, are owing to regional circulation changes that are predominantly a response to warming trends in the central tropical Pacific Ocean. Although other influences on circulation, locally-driven changes in sea ice, and direct radiative effects (at least in spring) must play a role, longer-term warming trends in West Antarctica may similarly be dominated by the influence of tropical forcing. Historical data ${ }^{31}$ show that JJA tropical SSTs have been characterized by a strong central Pacific warming over much of the 20th century (Supplementary Fig. S7a). We would thus expect West Antarctica to have warmed for the same period, as is found in reconstructed temperature fields since the 1950s (refs 2,3 ) and in proxy data from West Antarctic ice cores over the past century ${ }^{17,32}$. Furthermore, strong JJA warming in the central tropical Pacific is a common characteristic of general circulation model responses to scenarios of future greenhouse gas radiative forcing (Supplementary Fig. S7b; refs 33,34). Should the changes projected by these models over the next century be realized, the resulting atmospheric circulation changes will continue to strongly influence West Antarctic climate.

\section{Methods}

We use geopotential height and sea level pressure data from ECMWF, a combination of the ERA-40 (1979-2002) and ERA-Interim (2003-2009) reanalysis data $^{20}$. The two data sets show no discontinuity in the overlapping period (1988-2002). NCEP2 reanalysis data ${ }^{21}$ yields comparable results for circulation. Warming trends in NCEP2 are larger than in either ECMWF data or independent station and satellite data (though they are not statistically distinguishable). In general, both NCEP1 and NCEP2 products have been found to be less reliable in the Antarctic than ECMWF because of differences in data assimilation schemes ${ }^{19,35}$ We use sea surface temperature and sea ice data from HADISST ${ }^{36}$ and ERSSTv $3^{37}$. For figures showing regression of atmospheric circulation patterns with Antarctic surface temperature, we use data derived from thermal infrared channels of the Advanced Very High Resolution Radiometer (AVHRR) satellite ${ }^{2,22}$, which are entirely independent of the reanalysis data sets. For comparison, we also show surface and near-surface temperature data from NCEP2 and ECMWF, and from weather stations compiled by the Antarctic 'READER' project ${ }^{38}$.

We use maximum covariance analysis (MCA; refs 23,24) to capture the dominant coupled modes between Southern Hemisphere Z200 (equator to $\left.87.5^{\circ} \mathrm{S}\right)$ and tropical SST $\left(20^{\circ} \mathrm{N}\right.$ to $\left.20^{\circ} \mathrm{S}\right)$. The MCA between the Z200 and SST field is achieved by singular value decomposition of the temporal covariance matrix, using equal area (square root of cosine of latitude) weighting. The pairs of singular vectors describe the spatial patterns of each field. The corresponding squared singular value represents the squared covariance fraction (SCF) and indicates the relative importance of that pair of vectors in relationship to the total covariance in the two fields. The expansion coefficients obtained by projecting the singular vectors onto the original data fields depicts the temporal variation of the spatial patterns.
Received 26 October 2010; accepted 8 March 2011; published online 10 April 2011

\section{References}

1. Vaughan, D. G. et al. Recent rapid regional climate warming on the Antarctic Peninsula. Clim. Change 60, 243-274 (2003).

2. Steig, E. J. et al. Warming of the Antarctic ice sheet surface since the 1957 International Geophysical Year. Nature 457, 459-462 (2009).

3. Goose, H. et al. Consistent past half-century trends in the atmosphere, the sea ice and the ocean at high southern latitudes. Clim. Dyn. 33, 999-1016 (2009).

4. Cullather, R. I., Bromwich, D. H. \& VanWoert, M. L. Spatial and temporal variability of Antarctic precipitation from atmospheric methods. J. Clim. 11, 334-367 (1998).

5. Rignot, E. et al. Recent Antarctic ice mass loss from radar interferometry and regional climate modelling. Nature Geosci. 1, 106-110 (2008).

6. Thompson, D. W. J. \& Solomon, S. Interpretation of recent Southern Hemisphere climate change. Science 296, 895-899 (2002).

7. Marshall, G. J. et al. Causes of exceptional atmospheric circulation changes in the Southern Hemisphere. Geophys. Res. Lett. 31, L14205 (2004).

8. Kwok, R. \& Comiso, J. C. Spatial patterns of variability in Antarctic surface temperature: Connections to the Southern Hemisphere Annular Mode and the Southern Oscillation. Geophys. Res. Lett. 29, 1705 (2002).

9. Schneider, D. P., Steig, E. J. \& Comiso, J. C. Recent climate variability in Antarctica from satellite-derived temperature data. J. Clim. 17, 1569-1583 (2004)

10. Johanson, C. M. \& Fu, Q. Antarctic atmospheric temperature trend patterns from satellite observations. Geophys. Res. Lett. 34, L12703 (2007).

11. Karoly, D. J. Southern hemisphere circulation features associated with El Niño-Southern Oscillation events. J. Clim. 2, 1239-1252 (1989).

12. Garreaud, R. D. \& Battisti, D. S. Interannual ENSO and interdecadal ENSO-like variability in the Southern Hemisphere tropospheric circulation. J. Clim. 12, 2113-2123 (1999).

13. Harangozo, S. A. The relationship of Pacific deep tropical convection to the winter and springtime extratropical atmospheric circulation of the South Pacific in El Niño events. Geophys. Res. Lett. 31, L05206 (2004).

14. Bromwich, D. H., Monaghan, A. J. \& Guo, Z. Modelling the ENSO modulation of Antarctic Climate in the late 1990s with the Polar MM5. J. Clim. 17, 109-132 (2004)

15. Latif, M., Kleemann, R. \& Eckert, C. Greenhouse warming, decadal variability, or El Niño? An attempt to understand the anomalous 1990s. J. Clim. 10, 2221-2239 (1997).

16. Ashok, K., Behera, S. K., Rao, S. A., Weng, H. \& Yamagata, T. El Niño Modoki and its possible teleconnection. J. Geophys. Res. 112, C11007 (2007).

17. Schneider, D. P. \& Steig, E. J. Ice cores record significant 1940s Antarctic warmth related to tropical climate variability. Proc. Natl Acad. Sci. 105, 12154-12158 (2008).

18. Lachlan-Cope, T. \& Connolley, W. Teleconnections between the tropical Pacific and the Amundsen-Bellinghausens Sea: Role of the El Niño/Southern Oscillation. J. Geophys. Res. 111, D23101 (2006).

19. Bromwich, D. H., Fogt, R. L., Hodges, K. I. \& Walsh, J. E. A tropospheric assessment of the ERA-40, NCEP, and JRA-25 global reanalyses in the polar regions. J. Geophys. Res. 112, D10111 (2007).

20. Uppala, S. M. et al. The ERA-40 re-analysis. Q. J. R. Meteorol. Soc. 131, 2961-3012 (2005)

21. Kanamitsu, M. et al. NCEP-DOE AMIP-II Reanalysis (R-2). Bull. Am. Meteorol. Soc 83, 1631-1643 (2002).

22. Comiso, J. C. Variability and trends in Antarctic surface temperatures from in situ and satellite infrared measurements. J. Clim. 13, 1674-1696 (2000).

23. Bretherton, C. S., Smith, C. \& Wallace, J. M. An intercomparison of methods for finding coupled patterns in climate data. J. Clim. 5, 541-560 (1992).

24. Wallace, J. M., Smith, C. \& Bretherton, C. S. Singular value decomposition of wintertime sea surface temperature and 500-mb height anomalies. J. Clim. 5, 561-576 (1992)

25. Held, I. M. in Large-Scale Dynamical Processes in the Atmosphere (eds Hoskins, B. J. \& Pearce, R.) 127-168 (Academic, 1983).

26. Gill, A. E. Some simple solutions for heat induced tropical circulation. Q. J. R. Meteorol. Soc. 106, 447-462 (1980).

27. Mo, K. C. \& Higgins, R. W. The Pacific-South American modes and tropical convection during the Southern Hemisphere winter. Mon. Weath. Rev 126, 1581-1596 (1998)

28. Hoskins, B. J. \& Karoly, D. J. The steady linear response of a spherical atmosphere to thermal and orographic forcing. J. Atmos. Sci. 38, 1179-1196 (1981).

29. Yuan, X. \& Martinson, D. G. Antarctic sea ice extent variability and its global connectivity. J. Clim. 13, 1697-1717 (2000).

30. Roeckner, E. et al. Max Planck Institut für Meteorologie Report 218, 90 (1996).

31. Smith, T. M., Reynolds, R. W., Peterson, T. C. \& Lawrimore, J. Improvements to NOAA's historical merged land-ocean surface temperature analysis (1880-2006). J. Clim. 21, 2283-2296 (2008). 
32. Schneider, D. P. et al. Antarctic temperatures over the past two centuries from ice cores. Geophys. Res. Lett. 33, L16707 (2006).

33. Meehl, G. A. et al. in IPCC Climate Change 2007: The Physical Science Basis (eds Solomon, S. et al.) (Cambridge Univ. Press, 2007).

34. Xie, S-P. et al. Global warming pattern formation: Sea surface temperature and rainfall. J. Clim. 23, 966-986 (2010).

35. Bromwich, D. H. \& Fogt, R. L. Strong trends in the skill of the ERA-40 and NCEP-NCAR reanalysis in the high and midlatitudes of the Southern Hemisphere, 1958-2001. J. Clim. 17, 4603-4619 (2004).

36. Rayner, N. A. et al. Global analyses of sea surface temperature, sea ice, and night marine air temperature since the late nineteenth century. J. Geophys. Res 108, 4407 (2003).

37. Smith, T. M., Reynolds, R. W., Peterson, T. C. \&

Lawrimore, J. Improvements to NOAA's historical merged land-ocean surface temperature analysis (1880-2006). J. Clim. 21, 2283-2296 (2008).

38. Turner, J. et al. The SCAR READER Project: Toward a high-quality database of mean Antarctic meteorological observations. J. Clim. 17, 2890-2898 (2004).

\section{Acknowledgements}

This work was supported by the US National Science Foundation, grant numbers OPP-0837988 and 0963924. We thank G. Hoffman for providing the code for ECHAM4.6, and P. Hezel, A. Jenkins, G. H. Roe, D. P. Schneider and S. Schoenemann for fruitful comments.

\section{Author contributions}

Q.D. did the calculations, implemented the general circulation model experiments, created the figures, and led the writing of the paper. All authors contributed to the experimental design and writing of the paper.

\section{Additional information}

The authors declare no competing financial interests. Supplementary information accompanies this paper on www.nature.com/naturegeoscience. Reprints and permissions information is available online at http://npg.nature.com/reprintsandpermissions. Correspondence and requests for materials should be addressed to E.J.S. 
Winter warming inWest Antarctica caused by central tropical Pacific warming

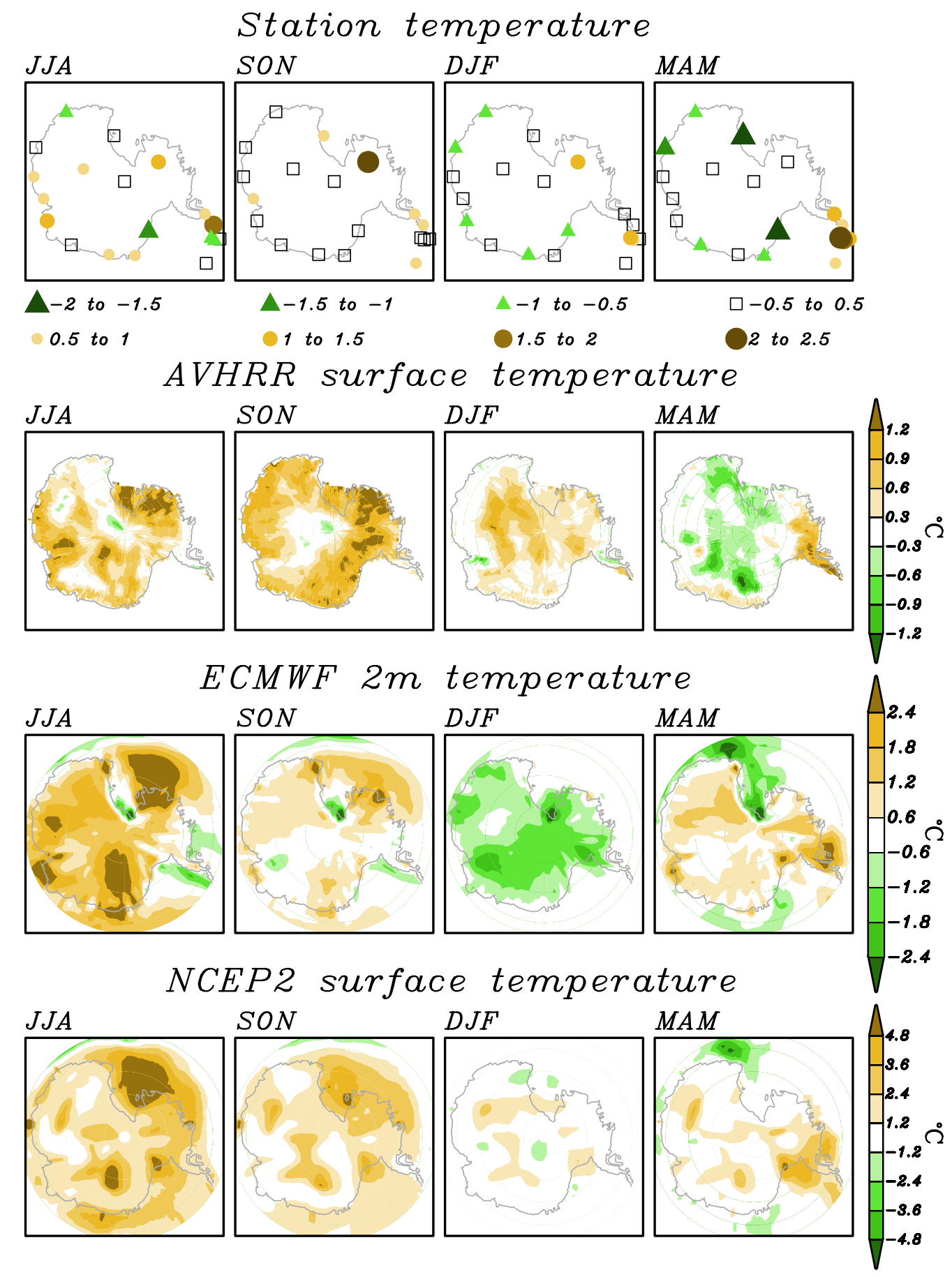

Figure S1. Seasonal Antarctic temperature change from different data sets.

Epochal difference (1994-2009 minus 1979-1993) of seasonal mean surface and near-surface temperature from weather stations, AVHRR satellite data, and ECMWF and NCEP2 reanalyses. For AVHRR, the epochs are 1982-1993 and 1994-2006. Note the different color scales for each data set. 
Supplementary Figures for Ding et al., "Winter warming in West Antarctica..."
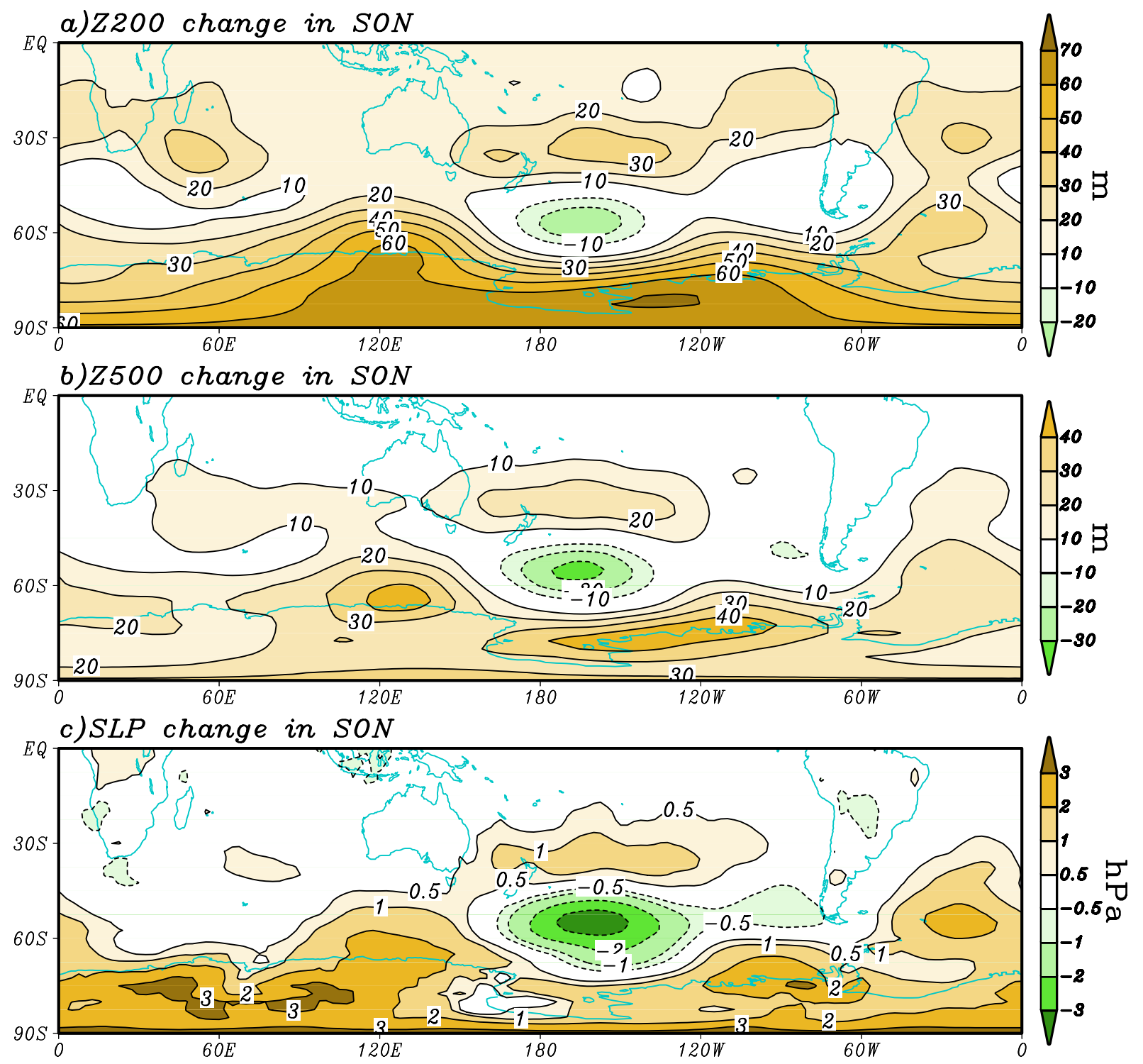

Figure S2. Geopotential height and sea level pressure change in austral spring.

Epochal difference (1994-2009 minus 1979-1993) of spring (SON) seasonal mean a) $200 \mathrm{hPa}$ geopotential height, b) $500 \mathrm{hPa}$ geopotential height and c) sea level pressure from ECMWF. 
Supplementary Figures for Ding et al., "Winter warming in West Antarctica..."

a)Model response to Indian Ocean SST (JJA Z200 and surface Temp/SLP)

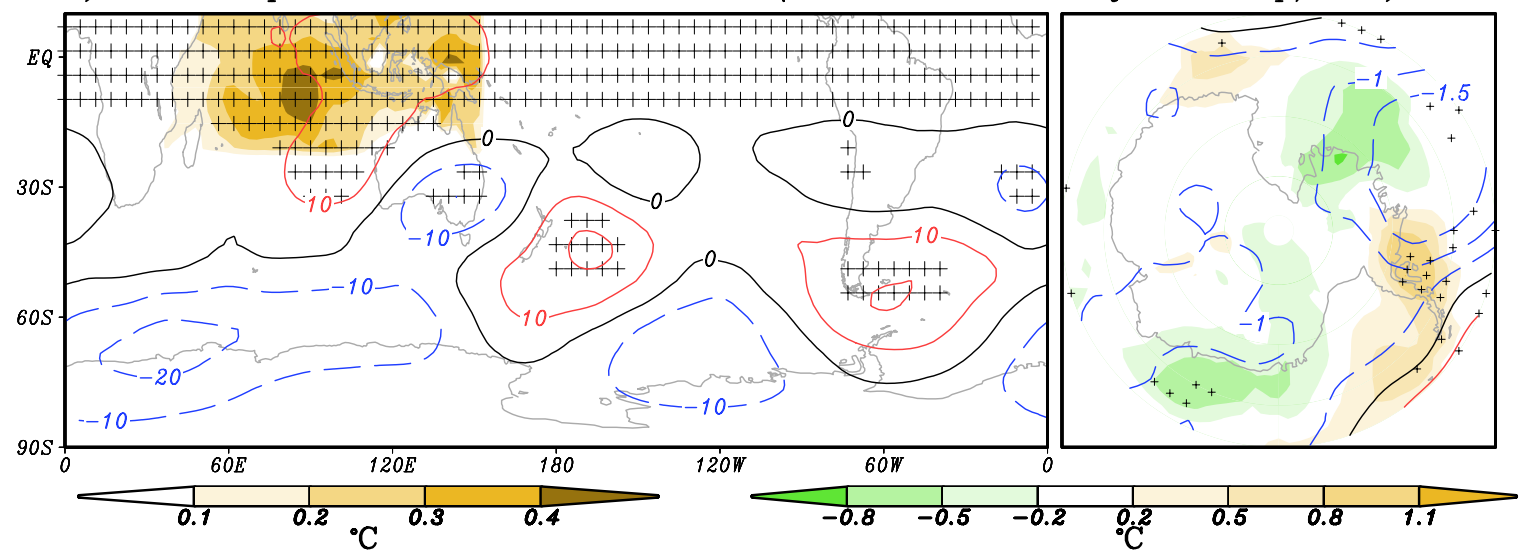

b)Model response to ENSO SST (JJA Z200 and surface Temp/SLP)

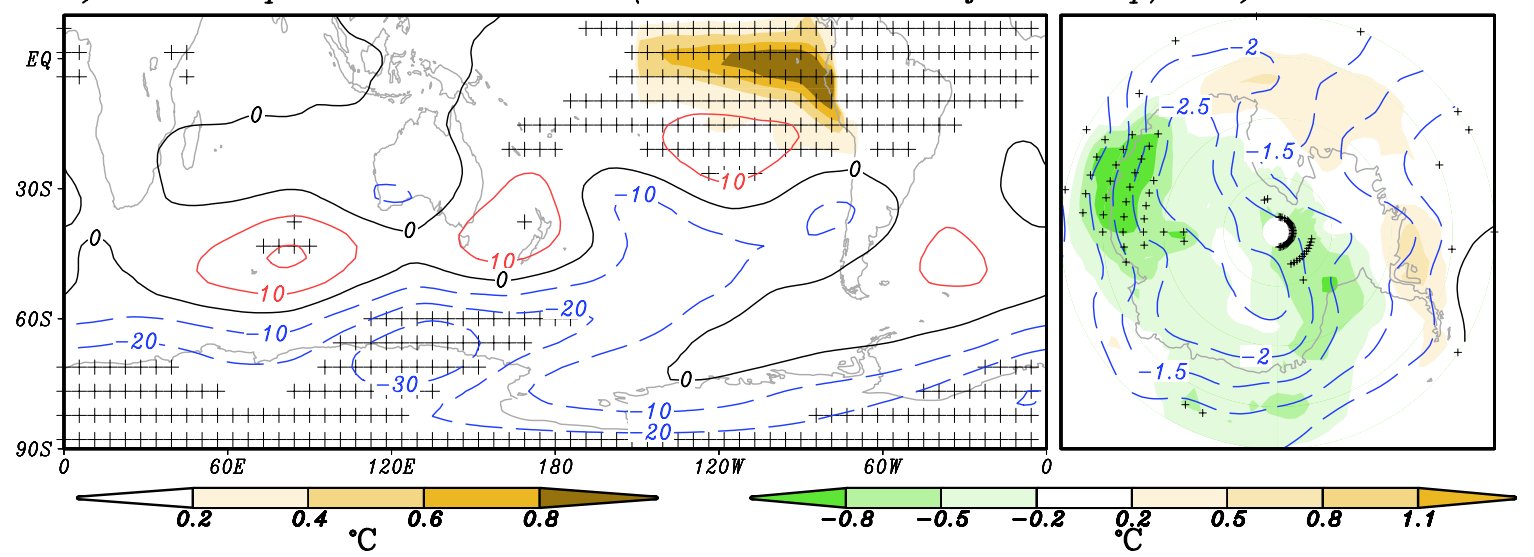

Figure S3. Response of ECHAM4.6 atmospheric model to anomalous warm sea surface temperature in the Indian Ocean and eastern tropical Pacific Ocean.

ECHAM4.6 model response to JJA SST forcing mimicking (a) the SST pattern of JJA mode 2 over the Indian ocean and (b) the ENSO forcing of JJA mode 1 over the equatorial Eastern Pacific. Colors show the tropical SST temperature forcing (left panels) and Antarctic region surface temperature response (right panels). Contours show Z200 height anomalies over the entire Southern Hemisphere (left panels), and SLP anomalies over the Antarctic region (right panels). '+' signs indicate where the Z200 (left) and surface temperature responses (right) are significant at greater than $99 \%$ confidence, based on a two-tailed Student's $t$-test. For the Indian Ocean, a +2 standard deviation forcing is used, because the response is quite weak. For the eastern Pacific, a +1 standard deviation forcing is used, as for the central Pacific forcing in Figure 4 (main text). 
Supplementary Figures for Ding et al., "Winter warming in West Antarctica..."

a)Epochal difference of JJA Z200 and surface Temp to SST forcing within CTP only

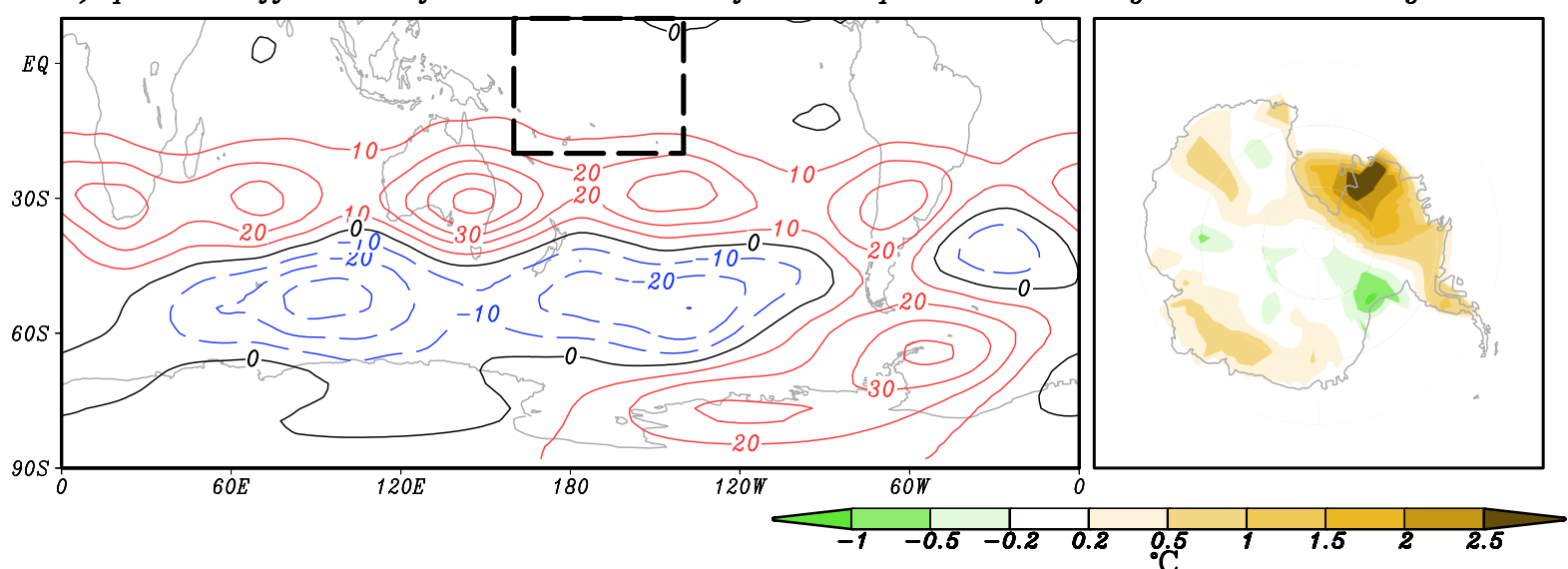

b)Epochal difference of JJA Z200 and surface Temp to global SST forcing without CTP forcing

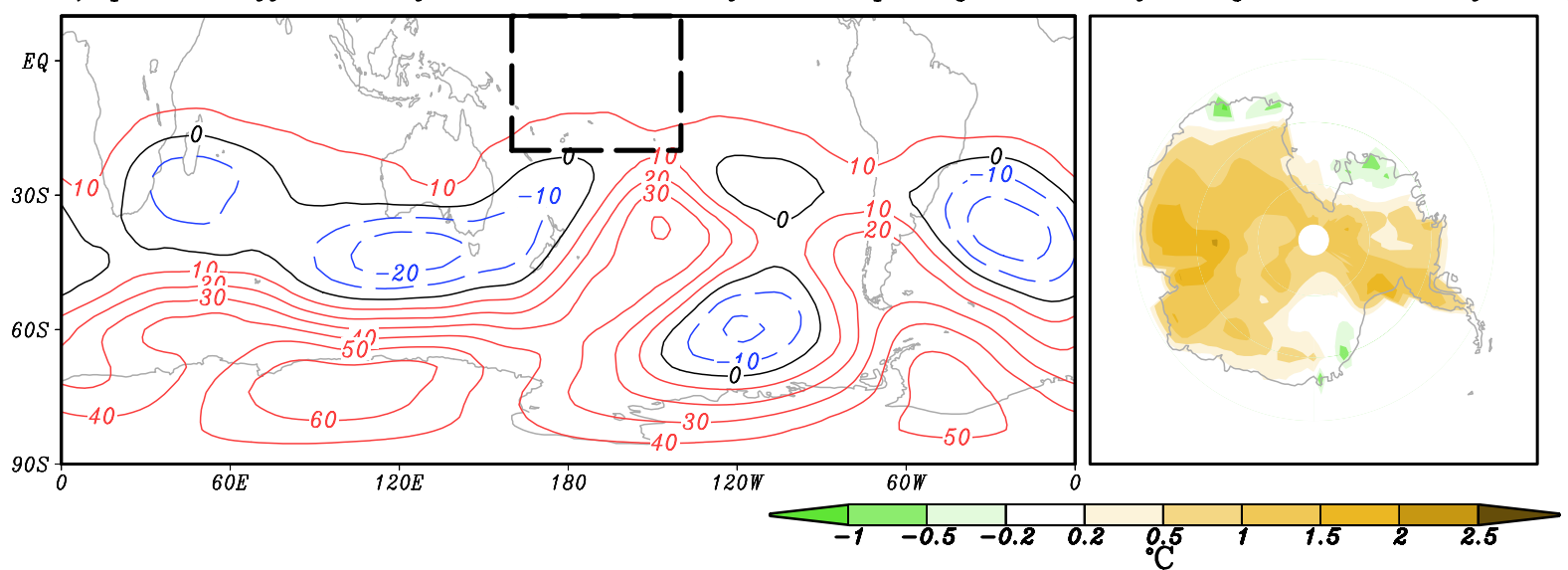

Figure S4. Epochal differences (1994-2009 minus 1979-1993) of response of ECHAM4.6 atmospheric model to observed SST winter forcing in a) the central tropical Pacific (CTP) and b) excluding the central tropical Pacific

Panel a) shows the $200 \mathrm{hPa}$ response (left) and the temperature response (right) in ECHAM4.6 to 31-year forcing of observed SST in JJA (ERSST3) in the central tropical Pacific region (outlined by box), with climatological SSTs used everywhere else. Panel b) shows the same but for climatological SSTs in the central tropical Pacific, and observed SSTs everywhere else. Contours are in meters. 
Supplementary Figures for Ding et al., "Winter warming in West Antarctica..."
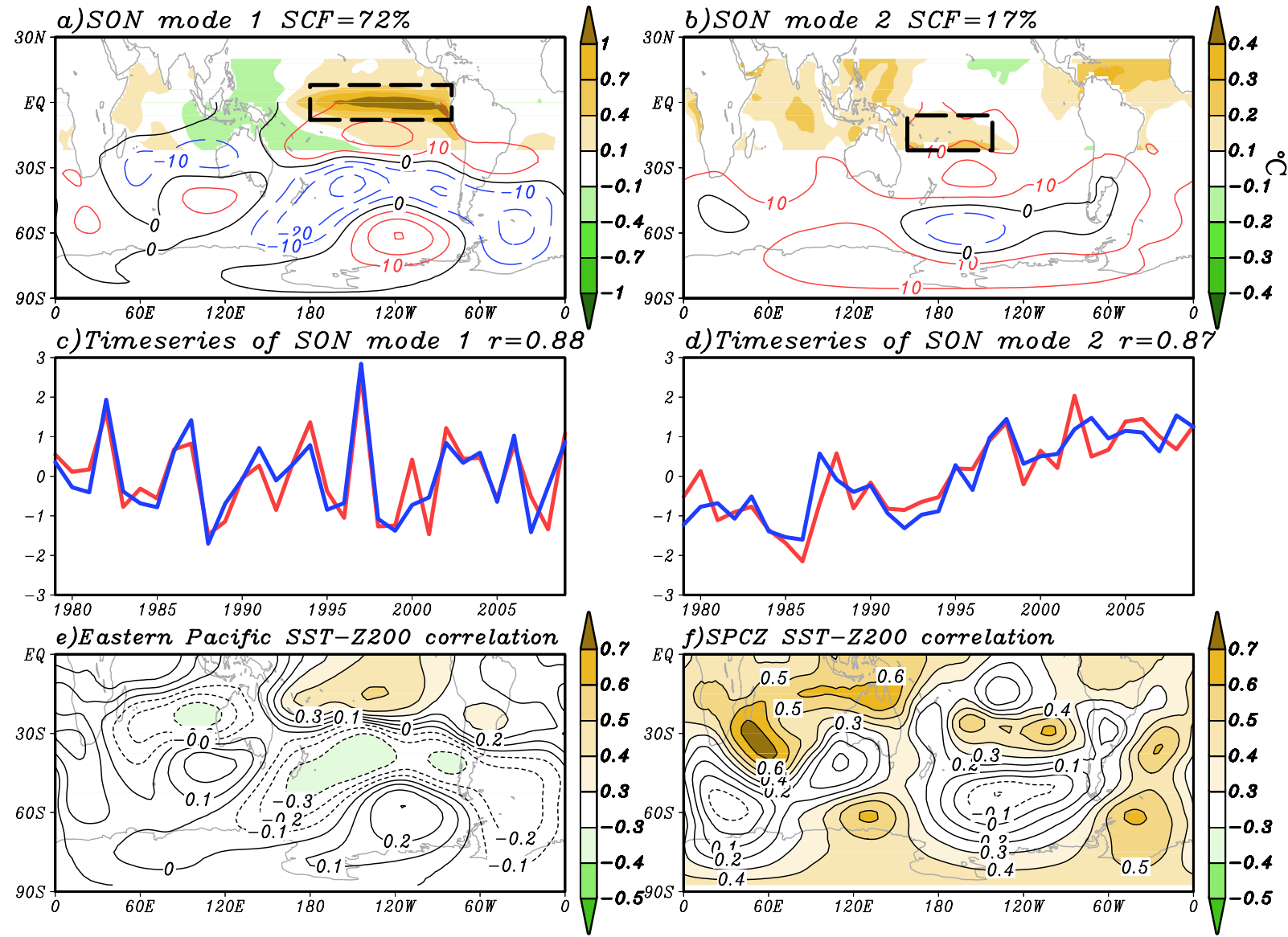

Figure S5. Principal modes of covarying tropical sea surface temperature and Southern Hemisphere circulation in austral spring.

Maximum covariance analysis (MCA) results for spring (SON) 1979-2009 Southern Hemisphere $200 \mathrm{hPa}$ geopotential heights $(\mathrm{Z} 200)$ and tropical $\left(20^{\circ} \mathrm{S}\right.$ to $\left.20^{\circ} \mathrm{N}\right)$ sea surface temperature (SST). a) mode 1 and b) mode 2 Z200 (contour interval 10m) and tropical SST (shading). c) mode 1 and d) mode 2 expansion coefficient of the Z200 (red) and SST mode (blue). e) correlation between Z200 and SST averaged over the eastern tropical Pacific $\left(180-280^{\circ} \mathrm{E}, 8^{\circ} \mathrm{S}-8^{\circ} \mathrm{N}\right.$, outlined in black in panel a). f) correlation between Z200 and SST averaged over the SPCZ region $\left(158-218^{\circ} \mathrm{E}\right.$, $22-6^{\circ} \mathrm{S}$, outlined in black in panel b). Amplitudes in (a) and (b) are scaled by one standard deviation of the corresponding time series in (c) and (d). Squared covariance fraction (SCF) and temporal correlation coefficient $(r)$ between the two expansion coefficient time series are indicated above each panel. 
Supplementary Figures for Ding et al., "Winter warming in West Antarctica..."

a) SON Z200

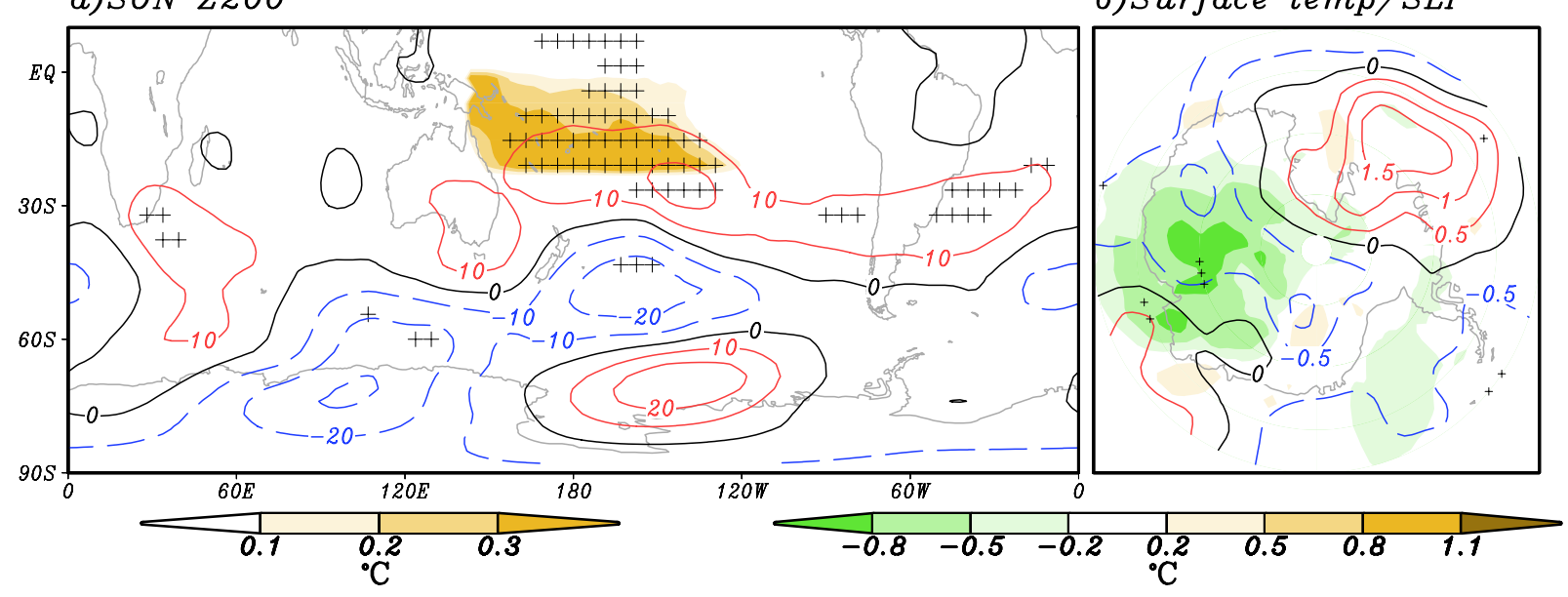

Figure S6. Response of ECHAM4.6 atmospheric model to anomalous warm central Pacific and SPCZ sea surface temperature in austral spring.

a) $200 \mathrm{hPa}$ geopotential height anomalies (contour interval $10 \mathrm{~m}$ ) over the Southern Hemisphere arising from +1 standard deviation anomalous SST forcing (shading); b) sea level pressure anomalies (contour interval $0.5 \mathrm{hPa}$ ) and surface temperature anomalies (shading) in the Antarctic region. Crosses denote regions of Z200 anomalies in panel (a) and surface temperature anomalies in panel (b), where the model response is above the $99 \%$ confidence level as assessed by a two-tailed Student's $t$-test. 
Supplementary Figures for Ding et al., "Winter warming in West Antarctica..."

a)JJA SST change in last 100 years (1960-2009 minus 1910-1959)

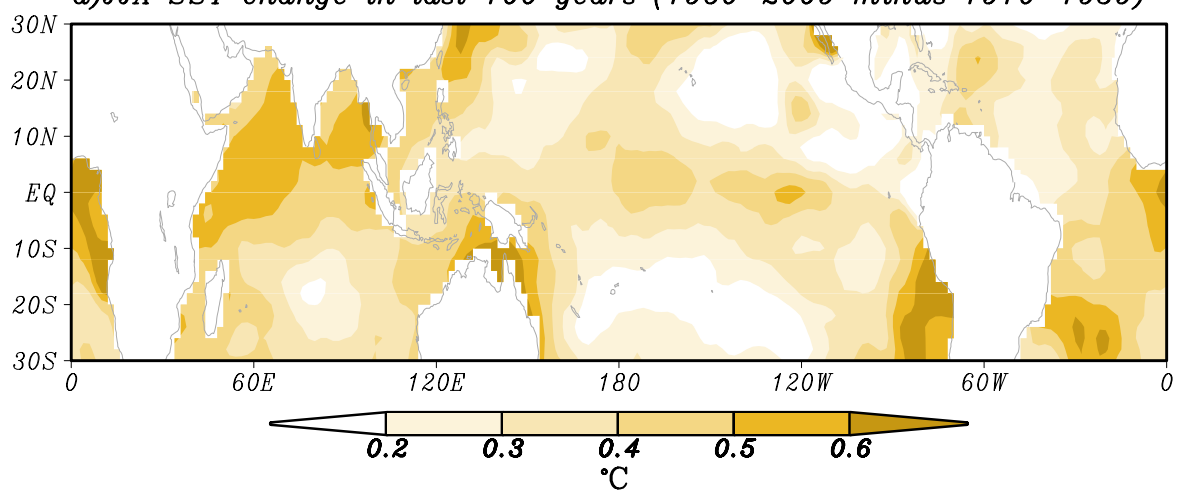

b)JJA SST change in ensemble IPCC run (2050 minus 2000)

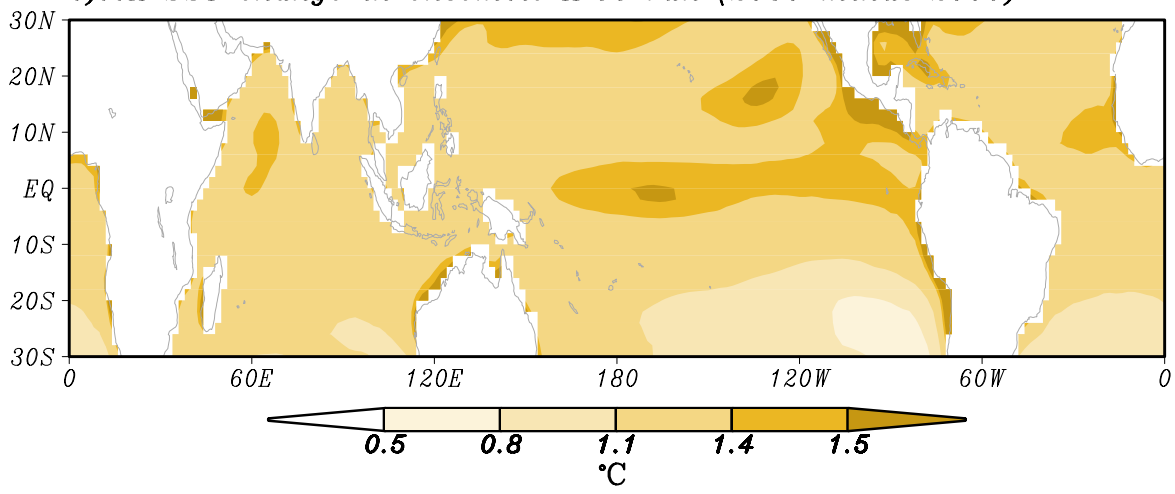

Figure S7. Tropical Pacific sea surface temperature anomalies in austral winter over the last century and in the future.

a) Epochal difference (1960-2009 - 1910-1959) of JJA tropical SST (30 S-30 $\mathrm{N}$ ) from ERSSTv3 data. A similar pattern of central tropical Pacific warning is seen for the most recent 60 years, and in HADSST2 data for the same time periods.

b) JJA SST change (2050 minus 2000) in an ensemble of coupled model runs under the IPCC A1B scenario. The model output in panel (b) is the ensemble mean from the 23 climate models used in the Intergovernmental Panel on Climate Change (IPCC) Fourth Assessment Report (AR4) and archived in the CMIP3 Multi-Model Dataset Archive at the Program for Climate Model Diagnosis and Intercomparison (PCMDI): www-pcmdi.llnl.gov/ ipcc/about_ipcc.php. The projection from this model ensemble suggests that the central tropical Pacific will be the region with the most significant warming in JJA. 